\title{
Healthy Living: Diabetes Care During Sick Days ${ }^{1}$
}

\author{
Jennifer Hillan, Emily Minton, and Linda B. Bobroff ${ }^{2}$
}

When you are sick, your blood glucose levels are harder to regulate. Being sick often causes blood glucose levels to rise, which can lead to serious health conditions. It is important to have a plan to manage your sick days so you are prepared ahead of time. Read on to learn more.

\section{Take Your Diabetes Medicines}

Take your insulin or oral diabetes medications even if you aren't eating as much as usual. Your blood glucose goes up when you are sick, so you may need more medication than usual. Your diabetes care team can help you regulate your medications when you are sick.

\section{Check Blood Glucose and Urine Ketones}

Check your blood glucose levels more frequently when you are sick. If you have type 1 diabetes, measure your blood glucose and urine ketones every four hours.
If you have type 2 diabetes, check your blood glucose at least four times a day (about every three hours). You should measure urine ketones if your blood glucose is higher than 300 , or as directed by your health care provider.

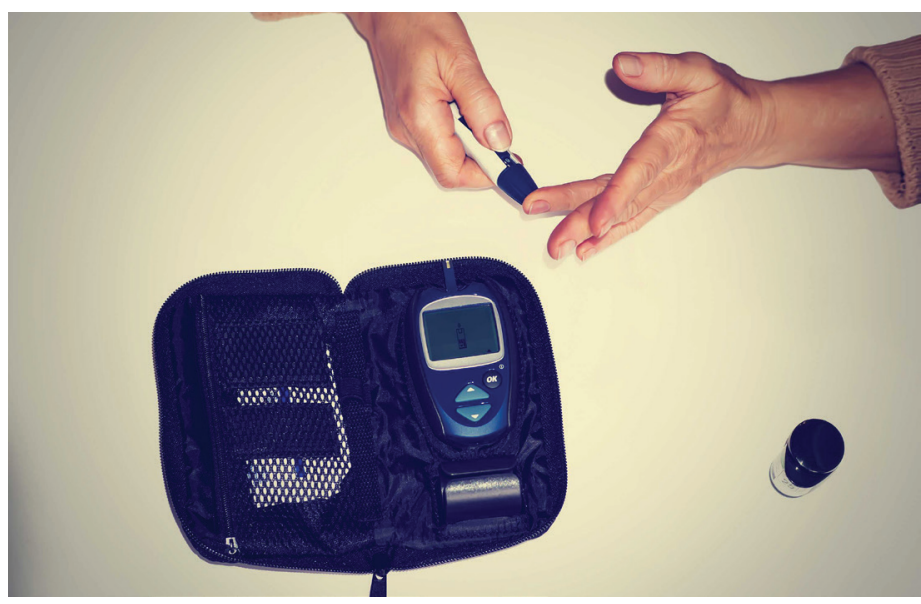

Figure 1. Check your blood glucose more often than usual when you are sick. Credits: BSIP/UIG

\section{Choose the Right Cold Medicine}

Some over-the-counter cold and flu medicines can affect blood glucose. Ask your pharmacist or health care provider about the best

1. La versión en español de este documento es Vida Saludable: Cuidados durante días de enfermedad (FCS8819-Span). This document is FCS8819, one in a series of the Department of Family, Youth and Community Sciences, UF/IFAS Extension. Original publication date December 2006. Revised February 2018. Visit the EDIS website at http://edis.ifas.ufl.edu.

2. Jennifer Hillan, MSH, RD, LD/N, former ENAFS nutrition educator; Emily Minton, BS, former ENAFS program coordinator; and Linda B. Bobroff, PhD, RDN, professor, Extension nutrition specialist, Department of Family, Youth and Community Sciences; UF/ IFAS Extension, Gainesville, FL 32611.

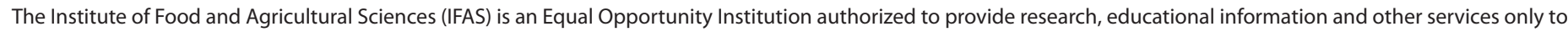

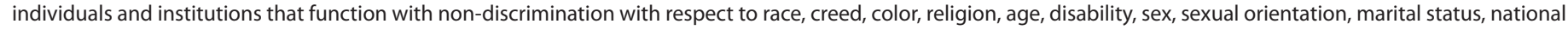
origin, political opinions or affiliations. For more information on obtaining other UF/IFAS Extension publications, contact your county's UF/IFAS Extension office. 
medication to take. Keep the right medicines on hand so you are prepared in case you get sick.

\section{Eat and Drink}

Stick to your regular meal plan if you can. If not, try to get your normal calorie intake by eating foods that are easy on the stomach, such as regular (not diet) gelatin, crackers, soup, and applesauce.

It is critical to drink enough fluids to keep yourself hydrated when you are sick. Drink a glass of liquid (alcohol-free and caffeine-free) every hour to stay well hydrated.

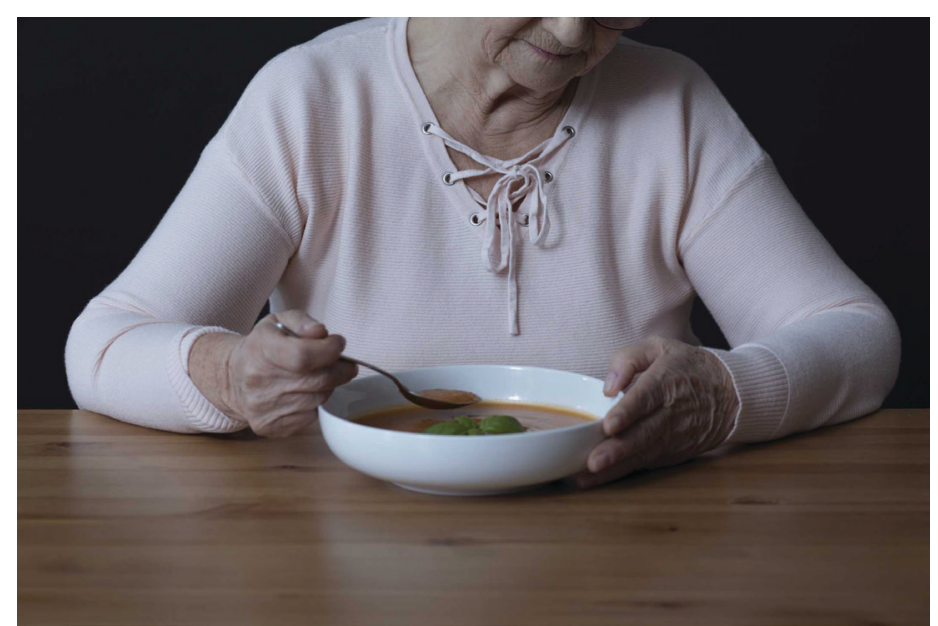

Figure 2. It's important to eat when you are sick, even when you don't feel much like eating. Broth and other liquids often are better choices than solid food.

Credits: Sheer Photo, Inc.

\section{Sick Day Foods}

Be prepared for sick days by having some of these foods and drinks on hand. Each one contains 10 to 15 grams of carbohydrates.

- 1 double-stick popsicle

- 1 cup sports drink

- 1 cup milk

- 1 cup soup

- $1 / 2$ cup fruit juice or regular (not diet) soda
- $1 / 2$ cup lemonade

- 6 saltine crackers

- 5 vanilla wafers

- 3 graham crackers

- 1 slice toast

- $1 / 2$ cup cooked cereal

- $1 / 2$ cup mashed potatoes

- $1 / 3$ cup frozen yogurt

- $1 / 2$ cup regular ice cream

- $1 / 4$ cup sherbet

- $1 / 2$ cup regular (not diet) gelatin

- 1/4 cup regular pudding

- $1 / 2$ cup sugar-free pudding

\section{When to Call Your Diabetes Team}

The American Diabetes Association suggests that you call someone on your diabetes care team if you have any of these symptoms while you are sick:

- "you've been sick or have had a fever for a couple of days and aren't getting better

- you've been vomiting or having diarrhea for more than 6 hours

- you have moderate to large amounts of ketones in your urine

- your glucose levels are higher than 240 even though you've taken the extra insulin your sick-day plan calls for 
- you take pills for your diabetes and your blood glucose level climbs to more than 240 before meals and stays there for more than 24 hours

- you have symptoms that might signal ketoacidosis, dehydration, or some other serious condition (for example, your chest hurts, you are having trouble breathing, your breath smells fruity, or your lips or tongue are dry and cracked)

- you aren't certain what to do to take care of yourself"

Source: American Diabetes Association (2017)

For more information, visit:

National Diabetes Education Program:

http://ndep.nih.gov/

UF/IFAS Extension:

http://solutionsforyourlife.ufl.edu

American Diabetes Association:

http://www.diabetes.org/living-with-diabetes/

\section{Reference}

American Diabetes Association. (2017). When you're sick. Accessed on January 22, 2018. http://www.diabetes.org/living-with-diabetes/ treatment-and-care/whos-on-your-healthcare-team/when-youre-sick.html

\section{Make a Plan}

Work with your diabetes care team to make a plan for your sick days.

Diabetes medications for sick days:

How often to measure blood glucose:

How often to measure urine ketones:

Suitable cold or flu medicines:

Meal plan:

Important phone numbers: 